\title{
Comparison of Point Intercept and Image Analysis for Monitoring Rangeland Transects
}

\author{
J. Cagney, ${ }^{1}$ S. E. Cox, ${ }^{2}$ and D. T. Booth ${ }^{3}$
}

Authors are ${ }^{1}$ Northwest Colorado District Manager, US Dept of the Interior, Bureau of Land Management, Grand Junction, CO 81506, USA; ${ }^{2}$ Biological Science Technician, US Dept of Agriculture, Agricultural Research Service, Otis Floyd Nursery Research Center, McMinnville, TN 38581, USA; and

${ }^{3}$ Rangeland Scientist, US Dept of Agriculture, Agricultural Research Service, High Plains Grasslands Research Station, 8408 Hildreth Rd, Cheyenne, WY 82009, USA.

\begin{abstract}
There is global recognition that sustainable land use requires monitoring that will detect change on a scale that protects the resource. That fundamental necessity is threatened where labor-intensive methods and high labor costs cause sampling deficiencies and increased Type-II error rates (false negatives). Ground-based imaging is a monitoring method that reduces monitoring labor costs. Nadir (vertical) images acquired with common digital cameras can be manually analyzed for cover using free software. We used an innovative field protocol to acquire standardized, freehand, nadir images (samples) of rangeland, then compared point intercept (PI) and image-analysis techniques. Between methods, precision (repeatability) across users was equivalent; cover measurements were often different, and the image-analysis technique took only a third as long to complete. Image analysis has several advantages over PI besides the reduced labor cost: Images are permanent resource records available for reanalysis if data are questioned, if software improves, or if management objectives change; and image analysis is less biased by moving vegetation, moving pointing devices, and bright vegetation color.
\end{abstract}

\section{Resumen}

Existe el reconocimiento mundial que la utilización sostenible del suelo requiere una supervisión que pueda detectar el cambio en una escala que proteja el recurso. La necesidad principal está en peligro cuando los métodos de labor intensivos y los altos costos de trabajo causan deficiencias en el muestreo y se incrementa la posibilidad de cometer el error Tipo-II (negativo falso). La proyección de imágenes terrestres es un método de supervisión que reduce los costos de la supervisión del trabajo. Las imágenes verticales adquiridas con cámaras digitales comunes pueden analizar la cobertura manualmente utilizando programas gratuitos. El estudio siguió un protocolo original de campo para adquirir las imágenes (muestras) del pastizal y después se compararon a un punto de intercepto (PI) y a las técnica de análisis de las imágenes. Entre los métodos, la precisión (capacidad de repetición) a través de los usuarios fue equivalente, las medidas de cobertura fueron diferentes, y la técnica del análisis de la imagen se llevó solamente un tercio del tiempo para realizarse. El análisis de las imágenes tiene varias ventajas sobre el PI además de la reducción el costo de mano de obra, las imágenes son expedientes permanentes del recurso disponibles para ser reanalizadas si los datos se cuestionan, y si los programas se mejoran. Asimismo, son una ventaja si los objetivos de manejo cambian, y el análisis de las imágenes tiene menos sesgos por el movimiento de la vegetación, movimiento de los dispositivos de señalamiento y el color brillante de la vegetación.

Key Words: cover measurement, land management, SamplePoint, Type-II error risk, vegetation sampling

\section{INTRODUCTION}

Natural resource monitoring is a vital aspect of sustainable resource management in all parts of the world (Levy and Madden 1933; Wilson 1963; Walker 1970; Glatzle et al. 1993; Stohlgren et al. 1998; Grabherr et al. 2000; Diaz et al. 2001). The specific goals for monitoring programs around the globe may differ, but generally they seek "...to provide the basis for consistent, uniform, and standard vegetation attribute sampling

Research was funded by the US Dept of the Interior, Bureau of Land Management, and US Dept of Agriculture, Agricultural Research Service.

Mention of proprietary products does not constitute a guarantee or warranty of products by USDI, USDA, or the authors, and does not imply approval to the exclusion of other suitable products. At the time of research, Cagney was Field Office Manager, US Dept of the Interior, Bureau of Land Management, Lander Field Office, Lander, WY 82520, USA; and Cox was Agricultural Science Technician, US Dept of Agriculture, Agricultural Research Service, High Plains Grasslands Research Station, 8408 Hildreth Rd, Cheyenne, WY 82009, USA.

Correspondence: Jim Cagney, USDI-BLM, Grand Junction, C0 81506, USA. Email: jcagney@ blm.gov that is economical, repeatable, statistically reliable, and technically adequate" (ITT 1996). Many programs use the point-intercept (PI) method when measuring ground cover to assess erosion risk or other key ecological parameters. PI popularity results from its speed relative to plot charting (Heady et al. 1959), simplicity, and repeatability (ITT 1996). Though faster than charting, it is a labor-intensive method. In countries where labor costs are high, the continued use of PI for landscape-scale assessments is impractical (West 1999)contributing to inadequate sampling, high Type-II error risk, and large data variance when data are collected by different people in different years (Vittoz and Guisan 2007) or through periods of phenological change. Less expensive, more reliable data-collection methods are needed. Half a century ago, Schultz et al. (1961) wrote that it would be "presumptuous to think that all conceivable break-throughs in sampling methodology have now been made." It follows that researchers should always seek to improve sampling method accuracy, precision, and economy (see also Stohlgren et al. 1998). Numerous 
authors have reported the utility of image analysis for vegetation cover measurements (a partial list might include Cooper 1924; Pierce and Eddleman 1973; Harris et al. 1996; Bennet et al. 2000; Louhaichi et al. 2001). Benefits of image analysis include 1) a permanent record of rangeland condition, 2) fast field-season acquisition with later analysis, and 3) ability to reanalyze with new techniques or if cover data are questioned. Booth et al. (2006a) reported that ground cover modeled on flat population posters was measured more quickly with the use of SamplePoint (SP) software than with PI, but method-time requirements had not been field tested. Despite its advantages, image analysis remains underutilized. Some have objected to carrying a camera stand or tripod in the field. Here, we tested an innovative, freehand protocol for obtaining nadir (vertical) images of the ground in a rangeland-monitoring case study that compared PI and SP methods for cover-measurement agreement, precision, and time. We also examined user covariables affecting the data.

\section{METHODS}

\section{Site Description}

The study site was in the Red Desert southwest of Rawlins, Wyoming, USA, at lat $41^{\circ} 43^{\prime} 30^{\prime \prime} \mathrm{N}$, long $107^{\circ} 26^{\prime} 40^{\prime \prime} \mathrm{W}$, on a Sandy High Plains Southeast ecological site characterized by deep, fine sandy loam and a big sagebrush/shortgrass plant community (Natural Resources Conservation Service 2009). Annual precipitation is $180-290 \mathrm{~mm}$.

\section{Monitoring Methods}

A 100-m tape was run between permanent posts to mark a transect used for both PI and SP data collection. All fieldwork was conducted between 9 and 12 June 2008. Fourteen users generated PI and SP data from the same transect.

Point Intercept (PI). Wire survey flags (pointers) with $1.6 \mathrm{~mm}$ wire diameter were lowered vertically next to a $100-\mathrm{m}$ tape at 20 -cm intervals (500 points) following the method reviewed by Herrick et al. (2005). Multiple canopy hits were recorded to ground level and to the following groups: cool-season bunchgrass, rhizomatous, and bluegrass (Poa L.), upland grass-like, broadleaf forb, cushion forb, annual forb, cactus, shrubs by species, alyssum (Alyssum desertorum Stapf), cheatgrass (Bromus tectorum L.), lichen (Xanthoparmelia Hale), rock, bare ground, and unknowns (Natural Resources Conservation Service [NRCS-ESD] 2009). The 14 users recorded PI data on paper forms. Seven transect readings were made by observer/recorder pairs, and seven were read and recorded by the same observer. For time accounting, where two people collaborated on reading, time-on-transect was doubled. Only aerial (first hit) cover was obtained from images; therefore, we used only PI first hits for comparing methods.

Image Collection. Fourteen users collected their own 20 nadir images (samples) at 5-m intervals along each transect with the use of a digital camera (Olympus E510, Olympus E330, Olympus SP-560UZ or Kodak P880; see Booth et al. 2005a). Resulting image resolution was camera-dependent, ranging from 0.23 to $0.26 \mathrm{~mm}$ ground-sample distance (GSD), the
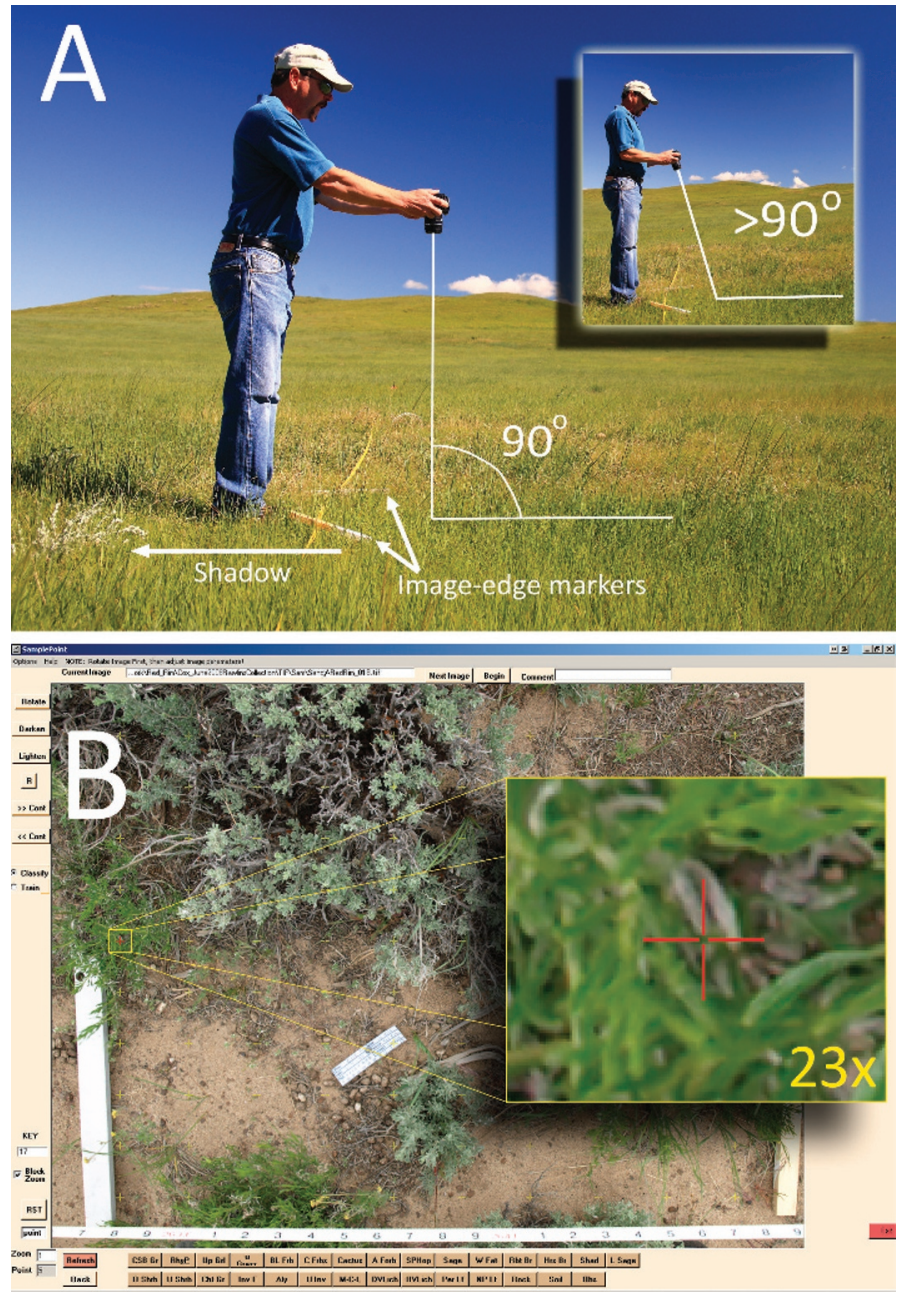

Figure 1. A, Technician acquiring nadir digital image along a stretched transect tape for later analysis with SamplePoint (SP). Good images will be nadir, shadow-free, in good focus, and taken when plant phenology allows easiest plant type or species detection. The use of two short sticks laid perpendicular along the tape at $82-\mathrm{cm}$ intervals allows users of different heights to capture equal-sized fields of view without a camera stand by using the sticks to frame the scene. The inlay shows the common mistake of "short-arming" the shot and taking the image offnadir. B, Screenshot of a project image being analyzed in SP. Note that the classification area is a single pixel in the image, and is the center pixel of a nine-pixel array outlined by the crosshair. When the point in question is magnified $\times 23$, the pixel is unquestionably representing rabbitbrush.

length of coverage for a single pixel. Users stood north of transects and photographed the south side to avoid shadows. Cameras were held at chest height, so the 100-m tape spanned the bottom of the LCD real-time display (Fig. 1A). All cameras had a 4:3 aspect ratio. For constant scale among users without the need for a tripod or stand, two white $2 \times 3 \times 20-\mathrm{cm}$ markers were placed $82 \mathrm{~cm}$ apart, the first marker placed at the $5-\mathrm{m}$ interval and the second $82 \mathrm{~cm}$ further (i.e., at 25 and $25.82 \mathrm{~m}$; Fig. 1A). Users adjusted the lens until the tape, and the markers placed perpendicular to it, were just visible before acquiring the image. This created a $0.5-\mathrm{m}^{2}(82 \times 61.5-\mathrm{cm})$ field of view (Fig. 1B). By adjusting the field of view to fit the 
Table 1. Mean cover \pm standard deviation (SD), 95\% confidence interval (CI), and limit of agreement (LOA) for six cover classes measured by 14 people with the use of both SamplePoint and Point Intercept methods along a single transect. LOAs define an interval that is interpreted as the interval in which $95 \%$ of measurements with both methods will occur; therefore a smaller LOA interval indicates better method agreement. Level of significance for paired $t$ test between the two data sets $(P)$ is also given. Bonferonni's correction for family-wise comparisons resulted in $\alpha=0.008$.

\begin{tabular}{|c|c|c|c|c|c|c|c|c|}
\hline \multirow[b]{2}{*}{ Class } & \multicolumn{2}{|c|}{ Sample point } & \multicolumn{2}{|c|}{ Point intercept } & \multirow[b]{2}{*}{$P$ value } & \multicolumn{3}{|c|}{ LOA } \\
\hline & Mean \pm SD & $95 \% \mathrm{Cl}$ & Mean \pm SD & $95 \% \mathrm{Cl}$ & & Lower & Upper & Interval \\
\hline Shrub & $25.4 \pm 3.6$ & 4.12 & $36.4 \pm 1.9$ & 2.24 & $<0.001$ & -16.2 & -5.8 & 10.4 \\
\hline Native forb & $4.3 \pm 1.6$ & 1.89 & $7.0 \pm 2.6$ & 2.97 & 0.002 & -7.9 & 2.6 & 10.6 \\
\hline Native grass & $5.7 \pm 1.8$ & 2.13 & $11.8 \pm 4.2$ & 4.89 & $<0.001$ & -15.8 & 3.5 & 19.4 \\
\hline Litter & $22.9 \pm 4.1$ & 4.77 & $17.1 \pm 3.9$ & 4.51 & 0.002 & 1.6 & 22.3 & 20.7 \\
\hline Bare ground & $38.4 \pm 6.6$ & 7.62 & $26.5 \pm 4.9$ & 5.7 & $<0.001$ & -5.2 & 16.8 & 21.9 \\
\hline Rock & $1.0 \pm 1.3$ & 1.49 & $0.03 \pm 0.1$ & 0.08 & 0.01 & -1.6 & 3.5 & 5.1 \\
\hline
\end{tabular}

markers, constant camera height above ground level, and constant lens focal length, were not required. Most observers recorded images as RAW format (Olympus Imaging Corporation 2007), and later converted to Tagged Image File Format (TIFF) for image analysis. However two observers took the initial images in TIFF and made no subsequent conversions.

SamplePoint (SP). SamplePoint software facilitates manual, pixel-based, image analysis from nadir digital images of any scale, and automatically records data to a spreadsheet (Booth et al. 2006a; SamplePoint 2009; Fig. 1B). Fourteen SP users measured cover from images at 25 points/image to yield 500 points/transect with the use of the same cover classes as used for the $500 \mathrm{PI}$ points/transect. All users recorded PI collection times; times for image collection, PI, and SP analysis times were recorded only by the three authors.

\section{Analysis}

Method cover-measurement means were compared for disagreement with the use of paired $t$ tests with Bonferonni's alpha correction for family-wise comparison. Because neither method is known to be more accurate, method agreement was assessed for each cover category by calculating limits of agreement (LOA; Bland and Altman 1986). A repeatability coefficient (RC), defined as 2 standard deviations (SD) of pairs of observation differences by method (Bland and Altman 1986) was computed with the use of Proc Mixed in SAS v7 (SAS Institute, Nashville, TN) with syntax based on Carstensen et al. (2008) for exchangeable replicates where $y=$ cover measurement, item = class (grass, forb, shrub, litter, soil, rock), method $=$ SP or PI, replicate $=$ users $1-14$. This model randomly paired the 14 users within each class to achieve the pairs of observations required for the RC calculation.

User-age bias was examined by regressing measurements with user age for both PI and SP and incorporating Bonferonni's alpha correction, and by $t$ tests of measurements for user groups split at 40 and 50 yr of age. Images (20) from three users were converted to high-quality Joint Photographic Experts Group (JPEG) format and analyzed the same as TIFF images to test the hypothesis of no difference in measurement due to format. As a control, data partially published in Booth et al. (2006a) on SamplePoint repeatability were used to create LOA for repeat analysis of 20 TIFF images, acquired in a similar way as above, by three users.

\section{RESULTS}

\section{Image Acquisition}

There were no significant problems encountered with the use of the freehand method. The most common errors were holding the camera too close to the chest so that the image was oblique, failing to set shutter speed appropriately to eliminate hand shake or compensate for wind, or not checking the bottom of the LCD display. The latter resulted in capturing area below the tape, including the photographer's shoes. These problems are resolved with practice.

\section{Cover Measurements}

Cover-measurement means from 14 PI and SP users were different for all classes except rock $(P<0.008)$, with PI showing greater plant cover, and SP showing greater litter and bare ground (Table 1).

\section{Agreement Analyses}

PI and SP did not agree well. Vegetation cover was consistently greater, as measured by PI, whereas litter, rock, and bare ground were consistently greater as measured by SP (Table 1, Fig. 2). For example, we expect SP bare-ground measurements will be $1.6-22.3 \%$ greater, $95 \%$ of the time, than PI measurements (Table 1). This indicates, but does not assign, method bias.

SP RC was 13.5, meaning that any user's measurement should be no more than $13.5 \%$ different than any other user's measurement, $95 \%$ of the time. PI RC was $11.3 \%$; thus both methods have high variation across users (Table 2), with PI precision being slightly greater.

User age was not correlated to cover measurements for any cover class $(r<0.5, n=14)$ for either method; however, users over $(n=7)$ and under $(n=7)$ age 40 had two differences among the 24 classes measured, but half of the measurements from users over $(n=5)$ and under $(n=9)$ age 50 were different $(P<0.1$, Table 3$)$. Age bias affected $83 \%$ and $39 \%$ of PI and SP measurements, respectively (Table 3 ). With both PI and SP, $6-7.5 \%$ more bare ground was measured by users over age 50 $(P<0.04)$. Age affected the RC for each method differently: SP $\mathrm{RC}$ was smaller (greater repeatability) for users over age 50, whereas PI RC was smaller for users under age 50 (Table 2).

Cover measurements from paired JPEG and TIFF images were correlated $(r=0.99)$ and had $\mathrm{a} \pm 2.75 \%$ LOA; thus a 

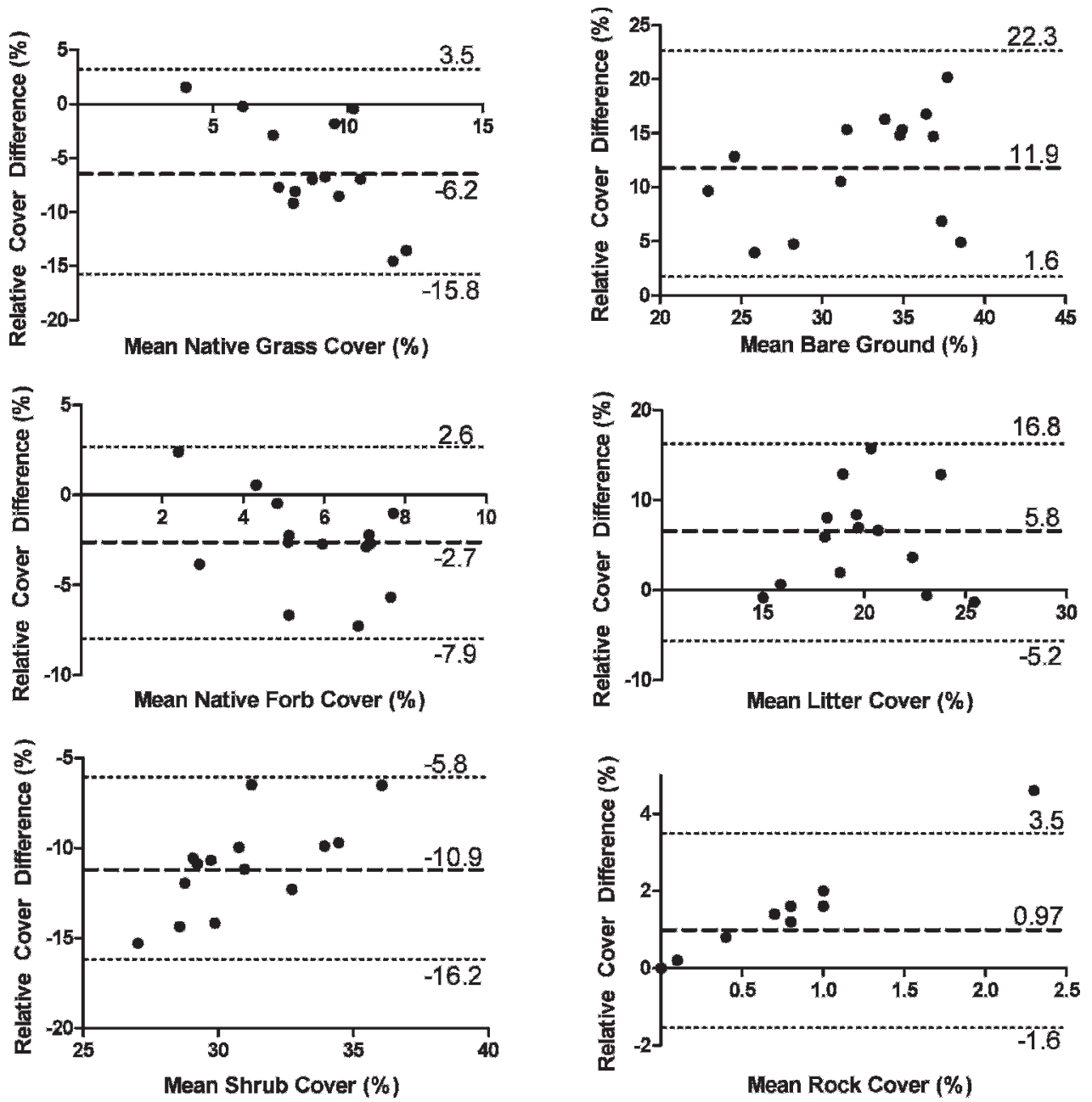

Figure 2. Bland-Altman plots of the difference between SamplePoint (SP) and Point Intercept (PI) method cover measurements (SP - PI; $y$ axis) against the measurement average of the two methods ( $x$ axis) for 14 users. The dashed line shows the mean measurement difference between methods, while the dotted lines show the upper and lower limits of agreement ( $\pm 2 \mathrm{SD}$ of the difference mean). Perfect agreement between the methods would be shown by all data points aligned along the dashed line. Difference means above zero indicate higher SP measurements. Vegetation (left plots) was almost always measured higher with PI, whereas litter, rock, and bare ground (right plots) were almost always measured higher with SP.

measurement from a JPEG-format image is expected to be within $2.75 \%$ of the measurement from the same scene in TIFF format, $95 \%$ of the time. Repeat SP measurements of TIFF images (data from Booth et al. 2006a) were also correlated $(r=0.995)$ with $\mathrm{a} \pm 3.10 \%$ LOA, meaning that any measurement made by User A on day 1 is expected to be within $3.10 \%$ of measurements made by User A on any other day.

\section{Time Requirements}

PI time included reading and transcribing paper data to spreadsheet. SP time included photo acquisition, download, analysis, and summary. PI transects were completed, on average, by single users and duos in $167 \mathrm{~min}(n=5$; two users didn't record time) and $99 \min (n=7)$ or 198 person-min, respectively. For all users, PI data transcription from paper to spreadsheet (separate from transect reading time), took an average of $110 \mathrm{~min}$. Image acquisition took $20 \mathrm{~min}(n=3)$. Downloading images and converting from RAW to TIFF required approximately $35 \mathrm{~min}$, but these are automated processes that do not take user attention for the full $35 \mathrm{~min}$. SP image classification averaged $62 \mathrm{~min} /$ transect with a few additional minutes for statistics generation within the software. Average time from start of transect to data in a spreadsheet was $296 \mathrm{~min}$ for PI and $108 \mathrm{~min}$ for SP $(n=3)$.

\section{DISCUSSION}

\section{Cover Measurements}

Smaller point sampling device contact areas increase accuracy (Wilson 1963, Cook and Stubendieck 1986, Booth et al. 2006c); but, because contact area is never zero, PI tends to overvalue standing cover (Cook and Stubendieck 1986). In this study, PI pointer-tip area was $2.01 \mathrm{~mm}^{2}$. Our finding that PI users recorded greater plant cover, and SP users recorded greater litter, rock, and bare ground (Table 1), is similar to greater plant-cover PI measurements obtained in method comparisons by Brakenhielm and Qinghong (1994), Korb et 
Table 2. Repeatability coefficients (RC) for SamplePoint (SP) and Point Intercept (PI) for all users, users under age 50, and users over age 50. A lower RC indicates higher method precision.

\begin{tabular}{lccc}
\hline \multicolumn{1}{c}{ Age } & SP & PI & $n$ \\
\hline All users & 13.5 & 11.3 & 168 \\
Under age 50 & 14.2 & 6.2 & 108 \\
Over age 50 & 5 & 10.8 & 60 \\
\hline
\end{tabular}

al. (2003), Laliberte et al. (2007), Symstad et al. (2008), and is in agreement with an earlier report (Booth et al. 2005a). SP also has a contact area (one pixel) greater than zero, but one dependent on camera resolution: a 10-megapixel camera used in this study had a sample area of $0.05 \mathrm{~mm}^{2}$, which is 40 times smaller than the contact point used for the PI method; a 21megapixel camera (Canon USA, Lake Success, NY) would have a sample area of $0.01 \mathrm{~mm}^{2}$, 201 times smaller than the PI pointer-tip area. As camera resolution continues to improve, the SP method comes ever closer to the ideal zero-area contact point. Herrick et al. (2006) reviewed evidence that PI is more precise (repeatable) than plot-based methods, but they and Stohlgren et al. (1998) found transect methods inadequate for early detection of invasive and rare species. Wind makes PI use more difficult (ITT 1996), often forcing users to make judgments about pinpoint contact. Booth et al. (2006c) described bright color bias in classification, a bias surely exacerbated by judgments made in high wind. SP classification points, however, are fixed, as are the plants in the images (even in wind, sufficient shutter speed can "freeze" plants in motion); therefore, color and other biases are less of a factor.

PI and SP showed equivalent $98 \%$ accuracy when tested on a 2D simplified vegetation-population poster, but this study suggests a difference when the methods are applied to 3D, realworld vegetation (Booth et al. 2006c); for example, PI bare ground averaged $12 \%$ less than SP bare ground (Table 1). SP always uses a 2D image for classification; thus there is no reason to suspect a change in accuracy from that reported by Booth et al. (2006c). Though bare ground is more or less 2D in a PI analysis, the context is $3 \mathrm{D}$, usually green, vegetation. A bright-color-user bias has been reported (Booth et al. 2006a, 2006c) and likely leads users to undercount bare ground. We conclude that SP, even though it is a plot method, is more accurate in a 3D world; but we concede there is no accepted standard for establishing real-world cover (Limb et al. 2007). Yet, given the findings of this study and those reviewed by Cook and Stubbendieck (1986), one may logically question whether PI-measured bare ground is being chronically underreported.

We report pixel coverage as a single number $\left(0.05 \mathrm{~mm}^{2}\right)$, but this value is only exact in the center of the image, whereas actual coverage increases linearly in all directions from center at a rate dictated by lens barrel distortion, an artifact of the curved lens. Normal-angle lenses exhibit greater barrel distortion than telephoto lenses, but in this study, the effect is moderated by 1) a normal focal length of $\sim 42^{\circ}$ and, 2) relatively short vegetation. Cover is a relative measurement unchanged by barrel distortion except where the vegetation height variation is significant relative to the camera height above ground (see Booth et al. 2006b for detailed discussion of barrel distortion in image analysis). We don't regard the effect
Table 3. Levels of significance ( $P$ values) for $t$ tests of cover measured by users over $(n=5)$ and under $(n=9)$ age 50 for both SamplePoint (SP) and Point Intercept (PI) methods. The measurement difference relative to the $<50$ age group is shown $(\Delta)$.

\begin{tabular}{lcccccc}
\hline & \multicolumn{2}{c}{ SP } & & \multicolumn{2}{c}{$\mathrm{PI}$} \\
\cline { 2 - 3 } \cline { 5 - 6 } \multicolumn{1}{c}{ Class } & $P$ & $\Delta$ & & $P$ & $\Delta$ \\
\hline Shrub & 0.08 & -3.5 & & 0.07 & -1.9 \\
Native forb & 0.01 & -2.1 & & 0.02 & -3.1 \\
Native grass & 0.22 & $\mathrm{~ns}$ & & 0.01 & -5.5 \\
Litter & 0.48 & $\mathrm{~ns}$ & & 0.02 & 4.7 \\
Bare ground & 0.03 & 7.5 & & 0.03 & 5.9 \\
Rock & 0.41 & $\mathrm{~ns}$ & & 0.29 & $\mathrm{~ns}$
\end{tabular}

${ }^{1}$ ns indicates not significant.

of barrel distortion as significant in this study, and note that if present, such an effect would result in greater vegetation cover from SP, which was not the case. Nevertheless, users should be aware that longer focal-length lenses reduce barrel distortion and are thus preferred, and in tall vegetation the use of a frame that can elevate a camera to $2 \mathrm{~m}$ above the ground will reduce the distortion effect (Booth 2005a, 2005b).

SP cannot measure cover for subcanopy. However, obtaining this level of detail via PI is very expensive relative to data utility. Many land managers use only first-hit PI data and a quadrat-based measure of species diversity. Image analysis can deliver foliar cover (or herbaceous basal cover if imaging occurs before canopy development), bare ground, a permanent photographic record of species composition, and greater sample numbers over a much larger sampling area than PIand in about a third of the time. Fiscal prudency dictates collection only of data that will be used. Multicanopy PI data have value, but if it is not utilized effectively-including statistically adequate sampling-why allocate resources to collect it?

\section{Agreement Analyses}

It is tempting to compare new methods to a traditional "standard" method and judge suitability on agreement with the standard. But if the standard method has high variance, such as PI $(\mathrm{RC}=11.3 \%)$, it would be surprising if the two methods did agree. Method repeatability limits the amount of agreement possible (Bland and Altman, 1986). Reluctance to embrace new methods often stems from a desire to maintain "data continuity," but if repeatability is low, does data continuity exist?

Our agreement analyses (Fig. 2) are evidence of biases and other factors reducing PI accuracy in a 3D world. The CIs and RCs for both methods likely result from differences in either species identification or user-perceived ground rules for cover classification. For example, User $A$ may consider any dead plant material to be litter, whereas User $B$ may consider attached, standing dead to be the plant to which it is still attached. Thus, litter cover can change drastically from year to year because of classification, not biology. Traditionally, temporal PI data established trend, and most often was collected by different people using their personal understanding of ground rules. Consider the potential error inherent in this protocol when it is known that PI cover measurements can vary 
$\pm 11.3 \%$ between users, even when those users have been briefed on the classification ground rules. If temporal PI data from different users are compared, any differences must be suspected of existing, at least in part and possibly in whole, because of low repeatability. Perceptive range managers fear this situation to the extent that they are often unwilling to rely on field data when faced with controversial decisions such as stocking rate changes. That fear can keep trend-monitoring data from being used, and optimum decision making is correspondingly affected. Such ground-rule problems can be eliminated by a single user classifying multiyear image sets at once, as is possible with SP.

SP does not correct for user bias, and in this study had comparable precision $(\mathrm{RC}=13.5 \%)$; but it does work off of a permanent image record that can be reanalyzed at any time. If transect images taken $10 \mathrm{yr}$ ago and $1 \mathrm{yr}$ ago are available, they can be analyzed by a single user to eliminate user bias. Temporal differences seen in this latter analysis are much more likely to be due to biology. Thus, data verifiability and the capability to significantly increase sampling, are key advantages of image-based monitoring.

Users over $50 \mathrm{yr}$ old consistently measured more bare ground with SP, and even more with PI. The SP finding affirms the age bias first reported by Booth et al. (2005b). This is the first report that age bias influences PI data.

Because the LOA between low-compression JPEG and TIFF image analysis was $2.75 \%$, and the LOA between replications of TIFF images was $3.10 \%$, we conclude that there is no advantage to using TIFF images with SP because the data indicate user inconsistency accounts for all of the observed difference. High-compression JPEG images might yield different results, and TIFF imagery is likely still the best choice for automated analysis.

\section{Time Requirements}

Because the largest cost of monitoring is transportation (Stohlgren et al. 1998), gathering more data per field trip reduces cost. Image acquisition in this study took only $1 / 8$ the time of PI data collection (20 min vs. $167 \mathrm{~min}$ ), suggesting about eight times more image data can be acquired per trip with SP. Additionally, time from transect to data spreadsheet is faster with SP. For equivalent time, not counting travel-time savings, almost three times more data can be generated with SP relative to PI (108 $\mathrm{min}$ vs. $296 \mathrm{~min} / \mathrm{transect}$ for full analysis). The difference is reduced if 1) only PI first hits are recorded and 2) digital devices are used for field data collection, eliminating the need for paper-to-spreadsheet transcription, though this option is often not practical because of required additional software, expense, training, and rapid device obsolescence. Rangeland professionals and ranchers have identified lack of time as the principle obstacle to monitoring (FernandezGimenez et al. 2005), emphasizing the benefit of time-efficient methods.

\section{Error Risk (Types I and II)}

A primary responsibility of professional rangeland managers, particularly those in the public sector where sustainability monitoring is required by nine national environmental laws passed between 1969 and 1988, is to test for change in plant communities to assess the effects of weather and management on resource condition and trend. The null hypothesis $\left(\mathrm{H}_{0}\right)$ in these tests is that of no ecologically important change over time. The risk of Type-I error-a false positive-(rejecting $\mathrm{H}_{0}$ when it should be accepted) is controlled by using the appropriate probability level (usually $P=0.05$ in resource management). Type-II error-a false negative-is accepting $\mathrm{H}_{0}$ when it should be rejected; that is, in concluding there is no change when ecologically important change has, in fact, occurred. Type-II error is controlled by sample numbers and distribution. If these are inadequate to represent the resource and its variations, then the false-negative risk of Type-II error increases. This is the usual case in rangeland management for the reasons noted in the Introduction. Use of PI and other conventional, time-intensive sampling methods worsen the tendency toward undersampling and sampling through periods of phenological incomparability, thereby increasing the Type-II error/false-negative risk. Conversely, the greater sampling rate possible with image-based monitoring makes false-negative risk reduction more practical.

\section{IMPLICATIONS}

This study demonstrated 1) the utility of freehand nadir-image acquisition, 2) that PI vegetation cover values were consistently greater than comparable SP values (when considered with the reviewed literature, this is a finding that implies bare ground is often undervalued in PI-based assessments), 3) that PI repeatability is slightly better, but comparable to that of SP, 4) that user age affects PI data to a greater extent than SP data, 5) that low-compression JPEG and TIFF images give equivalent results, and 6) that SP is more time efficient than PI. Though our results are from one area, the important factors of the study are not unique to any one ecological site, and we predict our enumerated findings are applicable everywhere. Freehand nadir image acquisition is a viable alternative to using a camera stand for general field monitoring. The utility and time savings of ground imaging and analysis methods are an opportunity for monitoring entities to increase sampling, reduce their Type-II error risk, and increase data comparability by obtaining same-phenology samples and same-person temporal analyses. Because the ability for a single user to access the permanent photographic record and to essentially "go back in time" and monitor rangeland plots from years past is so significant, and the method by which this is accomplished is both quicker and gives approximately equal precision across users relative to PI, we recommend that land managers adopt nadir plot image collection and digital analysis. Managers should be aware that accumulating evidence indicates that the age of the observer will affect the data, with older observers tending to identify more bare ground. Potential PI undervaluing of bare ground could serve to further erode the utility of low-sample-density PI data. Sustainable resource use depends on accurate measurements of key ecological indicators and on a full consideration of data legitimacy with regard to sampling method, timing, intensity, distribution, and biases; it requires recognizing the risk of, and guarding against, falsenegative conclusions that could result in continued resource degradation. 


\section{ACKNOWLEDGMENTS}

We thank the users from the US Department of the Interior, Bureau of Land Management; US Department of Agriculture (USDA), Natural Resource Conservation Service; and the University of Wyoming who assisted in data collection: M. Astle, E. Bainter, L. Bindell, M. Calton, C. Fifield, M. Gilbert, S. Karl, J. Likins, M. Murry, T. J. Murry, C. Newberry, C. Newman, C. Otto, M. Scott, H. Shultz, M. Smith, C. Strom, M. Vasquez, and A. Warren. R. Allen, Bureau of Land Management, provided input on statistical analysis. R. Limb, Department of Natural Resource Ecology and Management, Oklahoma State University, C. Moffet, USDA, Agricultural Research Service, N. Webb, Australia Commonwealth Science and Research Organization, L. K. VanAmburg, US Forest Service, and anonymous reviewers provided helpful manuscript reviews.

\section{LITERATURE CITED}

Bennet, L. T., T. S. Judd, And M. A. Adams. 2000. Close-range vertical photography for measuring cover changes in perennial grasslands. Journal of Range Management 53:675-678.

Bland, J. M., And D. G. Altman. 1986. Statistical methods for assessing agreement between two methods of clinical measurement. Lancet i:307-310.

Booth, D. T., S. E. Cox, and R. D. BerRyman. 2006a. Point sampling digital imagery with "SamplePoint." Environmental Monitoring and Assessment 123:97-108.

Booth, D. T., S. E. Cox, and R. D. Berryman. 2006b. Precision measurements from very-large scale aerial digital imagery. Environmental Monitoring and Assessment 112:293-307.

Booth, D. T., S. E. Cox, C. Fifield, M. Phillips, and N. Williamson. 2005a. Image analysis compared with other methods for measuring ground cover. Arid Land Research and Management 19:91-100.

Booth, D. T., S. E. Cox, AND D. E. Johnson. 2005b. Detection-threshold calibration and other factors influencing digital measurements of ground cover. Rangeland Ecology \& Management 58:598-604.

Booth, D. T., S. E. Cox, T. W. Meikle, and C. Fitzgerald. 2006c. The accuracy of ground cover measurements. Rangeland Ecology \& Management 59:179-188.

Brakenhielm, S., and L. Qinghong. 1994. Comparison of field methods in vegetation monitoring. Water, Air and Soil Pollution 79:75-87.

Carstensen, B., J. Simpson, And L. C. GuRRin. 2008. Statistical models for assessing agreement in method comparison studies with replicate measurements. International Journal of Biostatistics 4(1):Article 16.

Cook, C. W., AND J. StubendieCK. 1986. Range research: basic problems and techniques. Denver, CO, USA: Society for Range Management. $317 \mathrm{p}$.

Cooper, W. S. 1924. An apparatus for photographic recording of quadrats. Journal of Ecology 12:317-321.

Diaz, S. A., I. Noy-MeIR, and M. Cabido. 2001. Can grazing response of herbaceous plants be predicted from simple vegetative traits? Journal of Applied Ecology 38:497-508.

Fernandez-Gimenez, M. E., G. Ruyle, and S. J. McClaran. 2005. An evaluation of Arizona Cooperative Extension's rangeland monitoring program. Rangeland Ecology \& Management 58:89-98.

Glatzle, A., A. Mechel, and M. E. Vaz Lourenco. 1993. Botanical components of annual Mediterranean grassland as determined by point-intercept and clipping methods. Journal of Range Management 46:271-274.

Grabherr, G., M. Gottfried, and H. Pauli. 2000. GlORIA: A global observation research initiative in alpine environments. Mountain Research and Development 20(2):190-191.

Harris, N. R., S. H. Sharrow, and D. E. Johnson. 1996. Use of low-level remote sensing to understand tree/forage spatial interactions in agroforests. Geocarto International 11(3):81-92.
Heady, H. F., R. P. Gibbens, and R. W. Powell. 1959. Comparison of charting, line intercept, and line point methods of sampling shrub types of vegetation. Journal of Range Management 12:180-188.

Herrick, J. E., J. W. Van Zee, K. M. Havstad, L. M. Burkett, and W. G. WHITFORD. 2005. Monitoring manual for grassland, shrubland and savanna ecosystems. Volume I: Quick start. Tucson, AZ, USA: The University of Arizona Press. 36 p.

Herrick, J. E., G. E. Schuman, and A. Rango. 2006. Monitoring ecological processes for restoration projects. Journal for Nature Conservation 14:161171.

Interagency TeChnical Team (ITT). 1996. Sampling vegetation attributes, Interagency Technical Reference, Report BLM/RS/ST-96/002. Denver, CO, USA: US Dept of the Interior, Bureau of Land Management-National Applied Resources Science Center. 164 p.

Korb, J. E., W. W. Covington, and P. Z. Fule. 2003. Sampling techniques influence understory plan trajectories after restoration: An example from ponderosa pine restoration. Restoration Ecology 11:504-515.

Laliberte, A. S., A. Rango, J. E. Herrick, E. L. Fredrickson, and L. Burkett. 2007. An object-based image anlaysis approach for determining fractional cover of senescent and green vegetation with digital plot photography. Journal of Arid Environments 69:1-14.

Levy, E. B., and E. A. Madden. 1933. The point method of pasture analysis. New Zealand Journal of Agriculture 46:267-269.

Limb, R. F., K. R. Hickman, D. M. Engle, J. E. Norland, and S. D. Fuhlendorf. 2007. Digital photography: reduced investigator variation in visual obstruction measurements for southern tallgrass prairie. Rangeland Ecology \& Management 60:548-552.

Louhalchi, M., M. M. Borman, and D. E. Johnson. 2001. Spatially located platform and aerial photography for documentation of grazing impacts on wheat. Geocarto International 16(1):63-68.

Natural Resources Conservation Service. 2009. Ecological site descriptions. Available at: http://esis.sc.egov.usda.gov. Accessed 18 June 2009.

Olympus Imaging Corporation. 2007. E-510 digital camera instruction manual. Tokyo, Japan: Olympus Imaging Corp. 140 p.

Pierce, W. R., and L. E. Eddleman. 1973. A test of stereophotographic sampling in grasslands. Journal of Range Management 26:148-150.

SAMPLEPoINT. 2009. USDA Agricultural Research Service products and services. Available at http://www.ars.usda.gov/services/software/download.htm?softwareid $=246$. Accessed 18 June 2009.

Schultz, A. M., R. P. Gibbens, and L. Debano. 1961. Artificial populations for teaching and testing range techniques. Journal of Range Management 14:236-242.

Stohlgren, T. J., K. A. Bull, and K. A. Otsuki. 1998. Comparison of rangeland vegetation sampling techniques in the central grasslands. Journal of Range Management 51:164-172.

Symstad, A. J., C. L. Wienk, and A. D. Thorstenson. 2008. Precision, repeatability, and efficiency of two canopy-cover estimate methods in northern Great Plains vegetation. Rangeland Ecology \& Management 61:419-429.

Vittoz, P., And A. Guisan. 2007. How reliable is the monitoring of permanent vegetation plots? A test with multiple observers. Journal of Vegetation Science 18:413-422.

WALKER, B. H. 1970. An evaluation of eight methods of botanical analysis on grasslands in Rhodesia. Journal of Applied Ecology 7(3):403-416.

WILson, J. W. 1963. Errors resulting from thickness of point quadrats. Australian Journal of Botany 11:178-188.

WEST, N. E. 1999. Accounting for rangeland resources over entire landscapes. In: D. Eldridge and D. Freudenberger [EDS.]. Proceedings of the VI International Rangeland Congress; 19-23 July 1999; Aitkenvale, Queensland, Australia. p. 726-736. 